\title{
Towards a theoretical model of dashboard acceptance and use in healthcare domain
}

\author{
Mona Isazad Mashinchi ${ }^{1,2,3}$, Adegboyega Ojo ${ }^{4,5}$, Francis J. Sullivan²,3 \\ Data Science Institute, National University of Ireland Galway ${ }^{1}$, Prostate Cancer Institute ${ }^{2}$ \\ Galway Clinic ${ }^{3}$, Maynooth University School of Business ${ }^{4}$, \\ Department of Applied Informatics in Management, Faculty of Management and Economics, Gdańsk University of \\ Technology, Poland ${ }^{5}$ \\ Mona.Isazad@insight-centre.org, Adegboyega.ojo@mu.ie, Frank.sullivan@galwayclinic.com
}

\begin{abstract}
The objective of this paper is to investigate existing factors related to the decision to adopt and use of dashboards in the healthcare domain using a systematic literature review approach. The study is part of a larger initiative on how analytics dashboards can support decisions in value-based prostate cancer treatment and care. Although many studies have been undertaken to evaluate the implementation of health information technologies in the healthcare sector, as far as we know, none of these studies provides a framework for dashboards use in the healthcare context. We believe that the resulting model from our study provides the necessary first step in developing empirical evidence for the acceptance and use of the dashboards in the healthcare domain.
\end{abstract}

\section{Introduction}

In today's world, Information Technology (IT) is adopted and used in various aspects of healthcare (HC). The application of IT in the HC offers numbers of advantages such as improvement in patients' outcomes and safety, increase in revenue, decrease in errors and costs, and rise in the efficiency [1].

In the healthcare domain, many organisations are adopting and using decision aid tools. Studies show decision aids enable healthcare professionals to easily analyse and identify patterns in data and support them in better detection of anomalies as well as interpretation. If decision aid tools are used by patients, they can improve patients knowledge and involvement in decisions about their care, reduce conflict in decisions and should guide them toward more informed choices [2]-[4]. Moreover, advances in cognitive science and technology have led to increasing interest in the use of interactive visual information displays to support decision making in healthcare [2], [3], [5]. The interactive decision dashboards are one of the results of such advances [3]. Dashboards are used in various fields, including healthcare [2]. Dashboards in healthcare have been used to monitor the trend of the data and to improve the healthcare services and quality of care; to enhance the efficiency of care; to improve the adherence to various guidelines in HC organisations; to track and access to data in real-time and to improve the healthcare transparency. Dashboards, as data-driven decision support tools, can provide information in a particular format to decision-makers and can improve decision making (DM) by elaborating cognition and capitalising on human perceptual capabilities. Interactive dashboards enable their users to expose the most insightful information at a glance as well as providing users with a means to self-regulate information exposure and avoid information overload facing a large amount of data. Decision dashboards can quickly communicate information about decision alternatives by presenting factors which might matter to make decisions for its end users [2], [6].

However, despite the advantages associated with the use of dashboards in healthcare and the growing interest in their adoption, extant literature only provides anecdotal evidence on their use. They do not provide clarity on factors affecting their successful adoption and use for decision making. This study addresses this knowledge gap by investigating existing factors related to the decision to adopt and use dashboards in the healthcare. The result of the study is a theoretical model for evaluating dashboards' adoption, acceptance and use in the healthcare domain. We believe the recommended model can enhance evaluation studies in the area of health informatics and can improve finding related to technology acceptance in healthcare. 
The remainder of the paper is organised as follow; section 2 literature review, section 3 methodology. Section 4 analysis, and section 5 examines the results. The discussion is presented in section 6 , and finally, section 7 presents the conclusion.

\section{Literature review}

\subsection{Overview of health informatics}

Health informatics is a scientific field with the primary goal of improving clinical care within the use of information technology. The main focus of this field is to understand the potential application of computers in healthcare domain and to develop knowledge of the individual, group and organisational impacts on Information Technology (IT) development, adoption and use [7]. During the last few decades, various definitions have been established for health informatics. For example, Wyatt et al. [8], have noted that "medical informatics is the study and application of methods to improve the management of patient data, clinical knowledge, population data and other information relevant to patient care and community health". In another study, Haux [9] defined health informatics as a cross-discipline area where research is fundamentally drawn from information sciences, computer sciences, and medicine with the main focus on the design, development and test of health IT.

Analyses show the focus of a lot of prior research in the area of health informatics has been on evaluating the use of IT. The evaluation studies are one of the main parts of the technology development and implementation in health informatics which can potentially enhance the understanding of the role of IT and can support the development and delivery of technology with both clinical and economic advantages [10]. Among various kinds of evaluation studies in the area of health informatics, the evaluation of technology adoption, acceptance and use in healthcare is one of the main focuses of research within the domain of evaluation study. More specifically, within the health informatics field, the focus of a large number of studies and this research paper are on evaluating healthcare technology implementation, use and acceptance, which subsequently confirm the importance of evaluation in any system development and implementation.

The next section reviews the existing models which have been adopted to evaluate the adoption, acceptance and use of technology.

\subsection{Salient theories in technology adoption}

Theoretical models of IT adoption and use have widely been used in various contexts, such as, commerce, education, internet/mobile-banking, agriculture, insurance, e-government, and healthcare [11], However, there are only few studies which adopted such models to examine the dashboard adoption, acceptance and use in the healthcare (and even in other industries and sectors). Several models have been introduced on IT adoption, acceptance, and use (Figure 1). Each of these models attempts to define why individuals or organisations reject or adopt and accept a technology to use and explains stages for the adoption, acceptance, and actual use [12]-[15].

In 2003, Venkatesh et al. [16] compared and synthesized previous models into the unified theory of acceptance and use of technology (UTAUT), to achieve a greater understanding of technology acceptance and use [11]. In the UTAUT model, Performance expectancy, e.g., perceived usefulness, job fit, outcome expectation, extrinsic motivation, relative advantages; effort expectancy, e.g., perceived ease of use, complexity, ease of use; and social influence, e.g., internalization, identification, compliance, were determined as key factors for behavioural intention to use [16]. Furthermore, facilitating conditions, e.g., training, technical compatibility, provision of support in workplace, financial support; and behavioural intention were identified as key factors for use. Besides, age, gender, voluntariness, and experience were identified as moderating factors. According to [17], different combinations of these four factors were theorized and found to moderate various UTAUT relationships [16]. In 2012, Venkatesh et al. [18] introduced UTAUT2, in this new model, they adapted UTAUT to match new constructs in the context of consumer acceptance and use of technology [19].

In 2013, Wisdom et al. [14] provided a comprehensive multi-level framework to technology adoption, acceptance, and use. Wisdom et al. employed a narrative synthesis approach to summarize theories and constructs associated with innovation adoption in different domains. In their study, the authors analysed 20 key adoptions theoretical frameworks and summarized the key adoption constructs cross four levels of contexts (external, organizational, individual and innovation level). More recently, Venkatesh et al. [11] at 2016, have expanded previous models on technology acceptance and use to a multi-level technology acceptance and use. This model consists of three levels. A middle level containing the baseline model (BM) of UTAUT and two other levels, lower and higher part of the model, which highlights the importance of the individuallevel and higher-level contextual factors that influence the intention and use of the technology [11]. 
Furthermore, the New outcome mechanisms in this model refer to the new effect of behavioural intention and technology use [20].

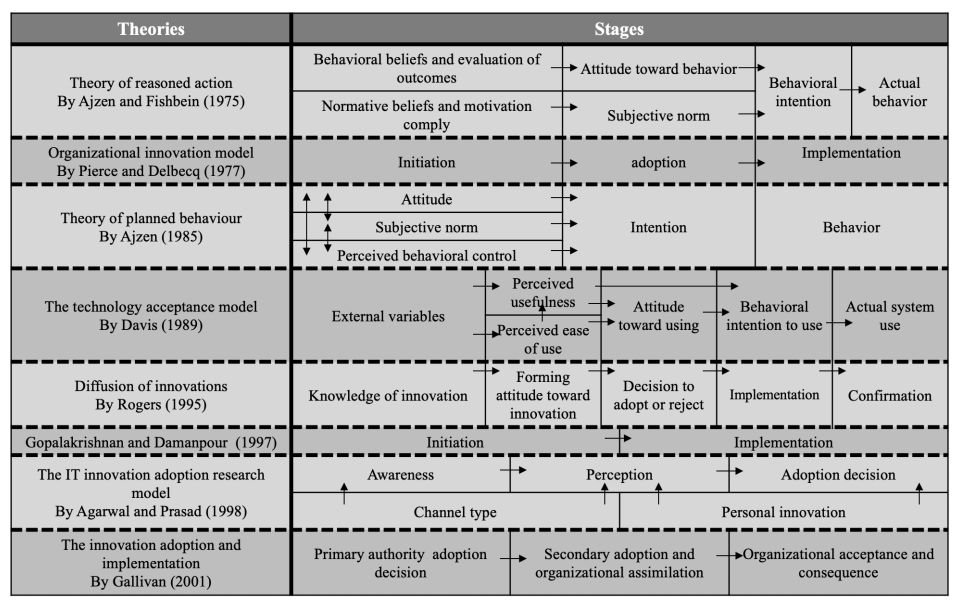

Figure 1. IT adoption, acceptance, and use

\section{Methodology}

\subsection{Research aim}

As mentioned earlier, notwithstanding dashboards' advantages in healthcare and increasing interest in their adoption and usage, the literature is replete with anecdotal evidence on their use, and it is not clear what are the decision-making factors affecting their successful adoption and use. So, guided by these gaps, this study aims to investigate existing factors affecting the decision to adopt, acceptance and use of dashboards in healthcare and to propose an evaluation model for dashboard adoption, acceptance and use in healthcare context. To meet this purpose, we aim to answer the following question.

1. What are the factors affecting the decision to adopt and use dashboards in healthcare?

\subsection{Search strategy}

The selection of databases was based on the following criteria: Accessibility to authors; Ranked as high-quality in bibliographic databases; Recommended by journal/conference review board and used in previous systematic literature reviews

So, considering these criteria, for this systematic literature review, we searched the following electronic databases "Scopus", "Web of Science", "CINHAL", "ACM", and "IEEE Digital Library" for the dates 2005 to June 2018. After choosing the right digital libraries, the next step was to caret a search string considering the research question and aim.

The main keywords used for searching studies included: "dashboard", "visualisation", "adopt", "accept", "health", and "healthcare".

The automatic search was developed using terms referring to the technology (dashboard* or visualisation*), combining them with (adopt* or accept*) and domain terms (health* or healthcare*). These terms were used to search studies' Topic, Abstract and Keywords.

The asterisk "*” symbol that broadens a search by finding words that start with the same letters was also used in automatic searching.

We also used the Booleans "AND", and "OR" to retrieve the related articles.

Moreover, a hand search of the reference' lists of identified papers from the automatic search was also conducted to find other related studies.

Due to limitation in time and resources available, the search was restricted to English studies. Finally, all search results were collated into the Mendeley library, where duplicate references were identified and removed.

\subsection{Studies inclusion criteria}

Studies were included in the review if they were: 1) Describing the adoption and implementation stage of the dashboard in the healthcare organisation; 2) 
Containing/explaining at least one element or attribute affecting the decision to adopt and use of dashboards; 3) Reporting the outcomes or evaluation of the use and the impact of dashboards; 4) Studies where dashboard could be viewed on a computer screen or via mobile phone, or interactive whiteboard; 5) Evaluation studies in the area of health informatics which adopted theories related to technology adoption acceptance and use. Studies were excluded if: 1) Reporting paperbased systems; 2) Do not present dashboard as the main intervention; 3) Are Thesis, Book, Grey papers, Notes, reviews $\S$ 4) Full texts are not available.

\subsection{Studies selection}

At the first stage, after importing the studies to Mendeley, out of the total 1260 studies, 75 studies were removed as they were duplicated. At the second stage, from the remaining 1185 studies, considering the inclusion and exclusion criteria, 260 full papers were chosen. Thirdly, inclusion and exclusion criteria were applied to the remaining 260 studies, which resulted in 35 studies. For validation, at the fourth stage, 10 studies were randomly selected (out of 260 studies) and reviewed by another reviewer. Any disagreements were resolved through discussion to arrive at unanimous decisions. At the fifth stage, 5 studies identified through manual searching. Finally, 40 papers were included in this review studies (Figure 2).

\section{Data analysis and synthesis}

The first reviewer coded the data from the included studies using a matrix created on an excel spreadsheet, beyond collecting basic article information (e.g., year, author, title, country), studies were coded based on the following aspects: 1) goals of adopting dashboards; 2) users of dashboards; 3) decision-making factors affected dashboard adoption and use; 4) outcomes of dashboards use; 5) applied tools' (dashboards) features or characteristics; 6) the theoretical model and approaches in dashboard design and development.

The second reviewer reviewed the extracted data. Any disagreements in coding were resolved through discussion.

In this review, narrative synthesis which has been employed in numerous systematic reviews has been used to summarise evidence from the literature. Generally, narrative synthesis consists of three main steps: 1) Data reduction (sub-group classification considering the evidence and the review questions); 2) Data comparison (an iterative process of making comparisons and exploring relationships); 3)
Conclusion and verification (checking main data sources for accuracy and confirmability).

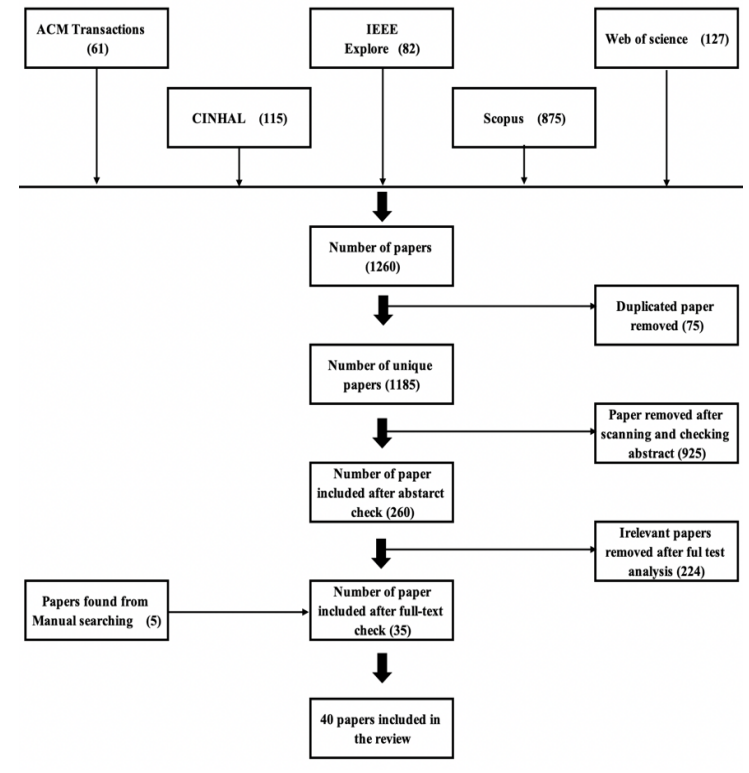

Figure 2. Flow diagram of included and excluded studies

\section{Results}

\subsection{Identified factors}

Dashboards can assist the human visual system to more efficiently process information with less cognitive effort [2], [3]. Good designed and developed dashboards can provide their users with information which is easier to read, perceive and recognise. They also can reduce the memory load by providing support for human short-and-long-term memory. Dashboards are useful for making sense of data and providing information in a nonlinear form to facilitate inferences and decision-making in the healthcare domain [6]. As suggested by Rind et al., visualisation tools and techniques 'combine the processing power of modern computers with human cognition and visual abilities to better support tasks [2].

Generally speaking, the use of dashboard in the healthcare organisation can improve collaboration and communication, reduce the time for decision making, facilitate documentation and increase the performance and efficiency of care. Moreover, if used by patients, they can facilitate patient-centred care by improving value, increase patients' safety and satisfaction and can support them in decision making and better communication with health professionals [6]. Our analysis show, although many case studies provided rich data on dashboard development, implementation and outcomes in healthcare, it is not clear what are the underlying factors affecting their successful adoption, 
use and outcomes. Also, many studies have evaluated the technology adoption in healthcare, but, limited studies have been undertaken to evaluate dashboards adoption and acceptance in the healthcare sector [3], [21]

So, despite dashboards' advantages and growing interest in adopting them, it is not clear what are the decision-making factors affecting their successful adoption and use. It is not clear what is the proper way to design and develop them. Moreover, there seem to be a certain amount of uncertainties about their effective integration with other systems, settings and practices in healthcare. Therefore, considering the gaps in the literature and this review's objective, we have analysed the studies. Based on the results from analysis, ten factors were identified from the selected studies (Table 1). We believe these factors play vital roles in the decision to adopt and use dashboards in healthcare organisations. A summary description of each factor can be found in the following:

\begin{tabular}{|c|c|}
\hline Higher level factors & Sub-factors \\
\hline \multirow{4}{*}{$\begin{array}{l}\text { External } \\
\text { environment [3], } \\
{[22]-[38]}\end{array}$} & $\begin{array}{l}\text { Government regulation in healthcare (e.g., patient- } \\
\text { centred care) }\end{array}$ \\
\hline & The movement toward more transparent reporting \\
\hline & $\begin{array}{l}\text { Regulation around the adoption and use of technology } \\
\text { in healthcare }\end{array}$ \\
\hline & $\begin{array}{l}\text { Policies and regulations related to the integration of } \\
\text { patient-generated health data into the health } \\
\text { information technologies }\end{array}$ \\
\hline \multirow{11}{*}{$\begin{array}{c}\text { Organisational } \\
{[2],[4],[22]-[24],} \\
{[27]-[54]}\end{array}$} & Compatibility of information technology infrastructure \\
\hline & Healthcare professionals' needs \\
\hline & Health professional champion for new technology \\
\hline & Difficulties with traditional systems \\
\hline & Resource commitment \\
\hline & Internal needs of the hospital \\
\hline & $\begin{array}{l}\text { Involvement of the end-user's in the design and } \\
\text { development process }\end{array}$ \\
\hline & Hospitals' norms, value, and regulations \\
\hline & Hospital volume \\
\hline & Hospital culture \\
\hline & Change management support \\
\hline \multirow{6}{*}{$\begin{array}{l}\text { Health professional } \\
\text { manager support } \\
{[22],[34]-[37],[44]}\end{array}$} & Allocating funds for training programs \\
\hline & Providing training and motivational programs \\
\hline & $\begin{array}{l}\text { Giving time to users to get use to the new system/ and } \\
\text { move from traditional system to the new one }\end{array}$ \\
\hline & $\begin{array}{c}\text { Managers support } \\
\end{array}$ \\
\hline & Technical supports \\
\hline & Health professionals' positive attitude toward change \\
\hline \multirow{4}{*}{$\begin{array}{l}\text { Trust } \\
{[22]}\end{array}$} & Information reliability \\
\hline & Secure data sharing \\
\hline & Authorised access \\
\hline & Secure and safe storing of data \\
\hline \multirow{7}{*}{$\begin{array}{c}\text { User } \\
{[3],[21]}\end{array}$} & Age, Education level \\
\hline & Graph literacy \\
\hline & Health literacy \\
\hline & Numeracy \\
\hline & Visual literacy \\
\hline & Previous knowledge and experience \\
\hline & Users' enthusiastic and confident \\
\hline \multirow{4}{*}{$\begin{array}{c}\text { Users beliefs } \\
{[3],[4],[21]-[31],} \\
{[38]-[40],[42],}\end{array}$} & Ease of use \\
\hline & Perceived usefulness \\
\hline & Perceived added value \\
\hline & Perceived helpfulness \\
\hline
\end{tabular}

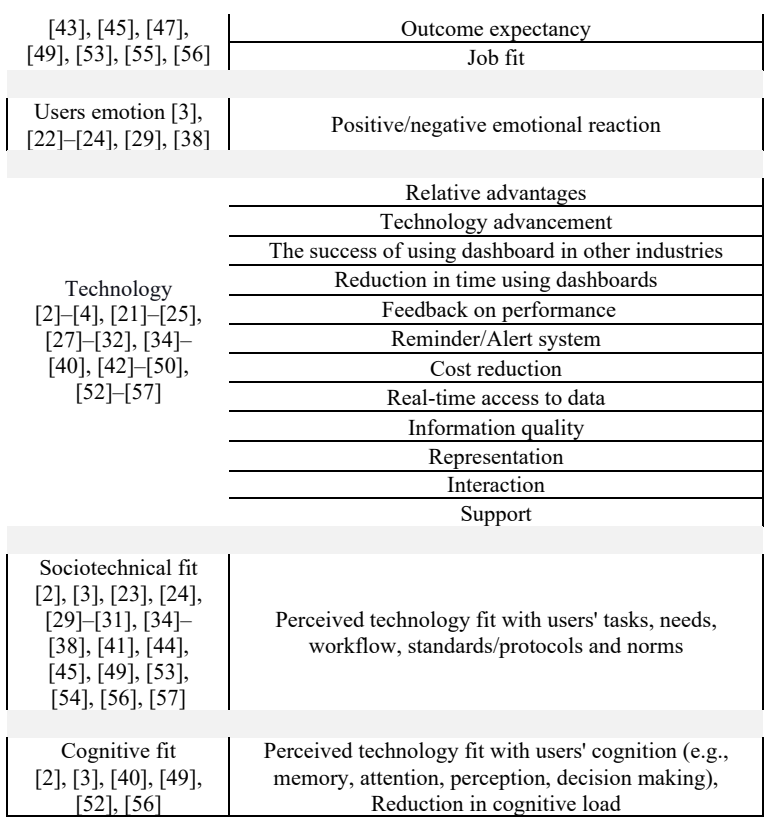

Table 1. Identified effective factors in decision to adopt and use dashboard

1) External environment. This factor is related to the location where technology adoption, implementation and use is happening. Factors in this category may force an organisation to adopt and implement new technology. Some factors and mechanisms which might lead to the adoption and implementation of new technology can be the regulation around technology adoption in healthcare and change in national and international policies.

2) Organisational. This factor is related to the characteristics of the organisation where the decision to adopt new technology, and its implementation and use occurs. Internal features of an organisation such as its capacity have vital roles in decision making about adoption. Some effective factors or mechanism in this category can be related to the organisational culture, change in norms and value, the managers' characteristic or new strategic planning.

3) Health professional managers support. These are the factors that help individuals and make it easier for them to use a new system to perform their task and to achieve their goal. This is related to the support which is provided by hospital staff and managers to endusers. Supports such as allocating funds for training programs and providing training and motivation programs can be classified in this category.

4) Trust. Trust can be defined as a degree to which a user believes that the provided information through the system is reliable, the data sharing through the system is secure, the information is only accessed by authorised people and data and information is stored in a secure and safe place. 
5) User. This factor is related to users' characteristics and capabilities. Such factors influence user perception and beliefs about using technology. For example, an older user with low numeracy and low health literacy might have different beliefs/perception about using a dashboard in comparison to a welleducated and younger person.

6) Users beliefs. This is related to users' perception and expectancies when using a new system. Some example related to users' beliefs can be user' perception about system usefulness, or perceived ease of use which all can be classified into two main construct, performance expectancy and effort expectancy.

7) Users emotion. This factor is related to user's emotional reaction when using a new system such as decision dashboard. More specifically, we found out; when a dashboard is presented to patients during their care process, it might trigger patients' emotional reaction which in turns might affect their intention and attitude toward using the system.

8) Cognitive fit. This factor is related to the cognitive fit of a developed system with users' capabilities and expectancies. We found out that in most analysed studies, one of the critical reasons that affected the successful adoption and use of a system was the reduction of the cognitive load while using the dashboard. Higher alignment between users' cognitive capabilities and the designed system reduce the cognitive load. More specifically, if a system or technology matches its users' cognitions, and natural way of thinking and acting, it is expected to reduce cognitive load. Cognitive load explains the mental effort that 'performing a task imposes on the cognitive system of a learner'.

Based on cognitive load theory, there are three types of cognitive load, intrinsic load, extraneous load and the germane load. Firstly, the Intrinsic cognitive load depends on the complexity of the task that users should perform. Secondly, the Extraneous cognitive load is related to the design of the presented data and system design. Finally, the German load is related to the mental burden of converting learned information into schemes in the working memory.

So, a simple system can reduce the cognitive load of completing a task. If users perceive a reduction in cognitive load, it can positively affect their performance and effort expectancy, which in turn increases the likelihood of accepting and using a particular system.

9) Sociotechnical fit. In addition to the importance of cognitive fit in developing systems which can improve performance and effort expectancy, we found out that the sociotechnical fit is another critical factor which has a vital role in technology adoption and acceptance.
This factor is related to the fit between the organisations' norms, structure, and users' needs, tasks and technology which called sociotechnical fit. The implementation and use of a new technology/system can change organisational structures (e.g., power structure), relations1hips (e.g., the relationship between patients and health professionals), communications, and can change the way care is delivered to patients.

So, if the aim is to develop and implement a decision support tool (dashboard) in the healthcare which is usable and acceptable, it should be fitted with users' task, needs, communication and organisations' norms, regulations and value. Finally, if a user perceives that a system is fitted with their needs, tasks and workflow, it enhances their performance and effort expectancy which in turn can lead to a higher level of acceptance, use.

10) Technology. Technology is related to the quality and characteristic of the dashboard. Some factors related to the technology, which might lead to the adoption and use decision are technology advancement, real-time access to data, relative advantages of using dashboards or the quality of information. As mentioned earlier, through the coding process, we tried to extract the characteristics, features and functionalities of dashboards that appeared to be effective in users' decision to adopt and to use them. Considering the literature, the common characteristic of dashboards or any other graphical visual interface is that 1) they have a visual interface that mediates the relationship between users and data, 2) the data on them has been presented in different formats and structures, 3) users can interactively manipulate the 78 data on dashboards to obtain answers for their questions or to perform tasks, 4) and they can get help from the support teams and the support features on system to finish their task. According to this definition, we identified four main components that comprise the interface, including Information Content, Representation (Format and structure), User Interaction, and Support. The quality and features of these components play essential roles in the successful acceptance and use of the dashboard by users.

In the following, first, we have provided definitions for each component. Secondly, considering the Nielsen's ten major heuristics that a good design interface should follow and our judgment, we have proposed 14 heuristics which can be seen in Table 2 (factors in bold proposed by authors). 


\begin{tabular}{|c|c|c|c|c|c|}
\hline Factors & Definition & 泀 & 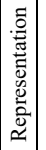 & & 咅 \\
\hline Visibility & $\begin{array}{l}\text { Colour and font on an interface should be } \\
\text { visible to users. } \\
\text { If a user selects an element on an interface, } \\
\text { they should receive a visible response from it. }\end{array}$ & & & & \\
\hline Match & $\begin{array}{l}\text { The design of a system, the content, and the } \\
\text { layout and } \\
\text { user's action on an interface should match } \\
\text { users experience, mental models. }\end{array}$ & & & & \\
\hline Human error & $\begin{array}{c}\text { It is about how to prevent an error that might } \\
\text { mistakenly happen (such as deleting, } \\
\text { removing). Such errors can be prevented by } \\
\text { showing a message or alert to users. Moreover, } \\
\text { a system should provide users with instructions } \\
\text { on how to fix an error. }\end{array}$ & & & & \\
\hline Consistency & $\begin{array}{l}\text { Colour, format, words and action on an } \\
\text { interface should be consistent. }\end{array}$ & & & & \\
\hline Acceptability & $\begin{array}{l}\text { Type of graph, choice of colours and wording } \\
\text { should be reasonable and based on the domain } \\
\text { needs. }\end{array}$ & & & & \\
\hline Memory & $\begin{array}{c}\text { The chunk of the data on an interface should be } \\
\text { based on human memory capabilities and with } \\
\text { most focus on recognition rather than recall. } \\
\text { For example, providing a short name for menu } \\
\text { items when the user hovers on them can reduce } \\
\text { the human memory load. }\end{array}$ & & & & \\
\hline Sequence & $\begin{array}{c}\text { The sequence of event and action should be } \\
\text { clear. Users should know where the starting } \\
\text { point and endpoint is. For a clear and precise } \\
\text { sequence, the system can provide users with } \\
\text { some cues, dialogue boxes, etc. }\end{array}$ & & & & \\
\hline Simplicity & $\begin{array}{l}\text { Graph, table, and interaction should be simple } \\
\text { without any distracting elements. }\end{array}$ & & & & \\
\hline Help & $\begin{array}{l}\text { A system should provide users with a help } \\
\text { section, such as training on how to work with } \\
\text { the system, enabling users to search } \\
\text { definition/guidance about unfamiliar elements } \\
\text { and actions on an interface }\end{array}$ & & & & \\
\hline Flexibility & $\begin{array}{l}\text { If possible, users should be able to add or } \\
\text { remove function, change the view of data, } \\
\text { colours and font size. }\end{array}$ & & & & \\
\hline Narrative sequence & $\begin{array}{l}\text { The system design, the sequence of the } \\
\text { information and graphs should be based on the } \\
\text { routines. For example, in the case of using a } \\
\text { dashboard for patients visit, the design and the } \\
\text { sequence of information should be based on } \\
\text { the real-world conversation between the doctor } \\
\text { and patients }\end{array}$ & & & & \\
\hline Understandability & $\begin{array}{c}\text { Wording, graphs and language should be } \\
\text { simple and understandable. }\end{array}$ & & & & \\
\hline Relevance & $\begin{array}{l}\text { The displayed data on the dashboard should be } \\
\text { relevant to the users. }\end{array}$ & & & & \\
\hline Importance & $\begin{array}{l}\text { The displayed data on the dashboard should be } \\
\text { based on users' needs and should be important } \\
\text { to them. }\end{array}$ & & & & \\
\hline
\end{tabular}

Table 2. 14 Heuristics for dashboard design

Information content: Information component of an interface is related to the types of data which going to be encoded and displayed on an interface. As the types of data determine how the data should/can be viewed on an interface; this component is significantly affecting the representation and interaction component of an interface.

Representation (Format and structure): Representation components of an interface is about data encoding and structure on an interface. We have divided the representation component of an interface into two dimensions: including format and structure. The format dimension of an interface is about how the data has been encoded. The format is the basic unit of an interface space and is about the mode of data presentation such as image, sound, graphs and icons on the interface. The structure dimension of an interface is about the layout, position of heading, and sub-heading, the sequence of information.

Use Interaction: This component of an interface is about users' actions on an interface and the responses which they receive from the interface. Possible action of a user on an interface can be filtering, drilling, navigating, zooming etc. It is also related to the physical occurrences (e.g., clicking, swiping, dragging, tapping) that users perform, to perform an action on an interface (for example filtering).

Support: This component of an interface mainly depends on the support which receives form providers. However, in this study, the focus is on the support which is provided by the technology design and characteristics to its end-users, such as the help section, training video on an interface.

\subsection{The proposed theoretical model of dashboard acceptance and use in healthcare}

As presented in previous sections, in this study, the aim was to identify decision-making factors which affect the decision to adopt and use the dashboard in healthcare and to propose a model for the dashboard acceptance and use in healthcare. In Figure 3 , the proposed theoretical model of user acceptance and use of dashboard in healthcare can be seen. The proposed model was developed after reviewing existing models and theories of user acceptance (section 2), and the identified factors and relationships from analysis (section 5.1). Finally, we propose 12 Hypotheses as follow:

H1.1: The perceived reduction in cognitive load (PRCL) fit positively affect the effort expectancy

H1.2: The perceived reduction in cognitive load (PRCL) fit positively affect the performance expectancy.

H2.1: The perceived sociotechnical fit (PSF) positively affect the effort expectancy.

H2.2: The perceived sociotechnical fit (PSF) positively affect the performance expectancy.

H3: The support component (SC) of an interface positively affect the intention to use.

H4: The interaction component (ItC) of an interface positively affect effort expectancy. 
H5: The information content component (IcC) of an interface positively affect the performance expectancy.

H6: The representation component (RC) of an interface positively affect performance expectancy. H7: Health professional Managers Support (HMS) positively affect the intention to use.
H8: Users trust positively affect the intention to use. H9: Users positive emotional (PE) reaction positively affect the intention to use.

H10: Users negative emotional (NE) reaction negatively affect the intention to use.

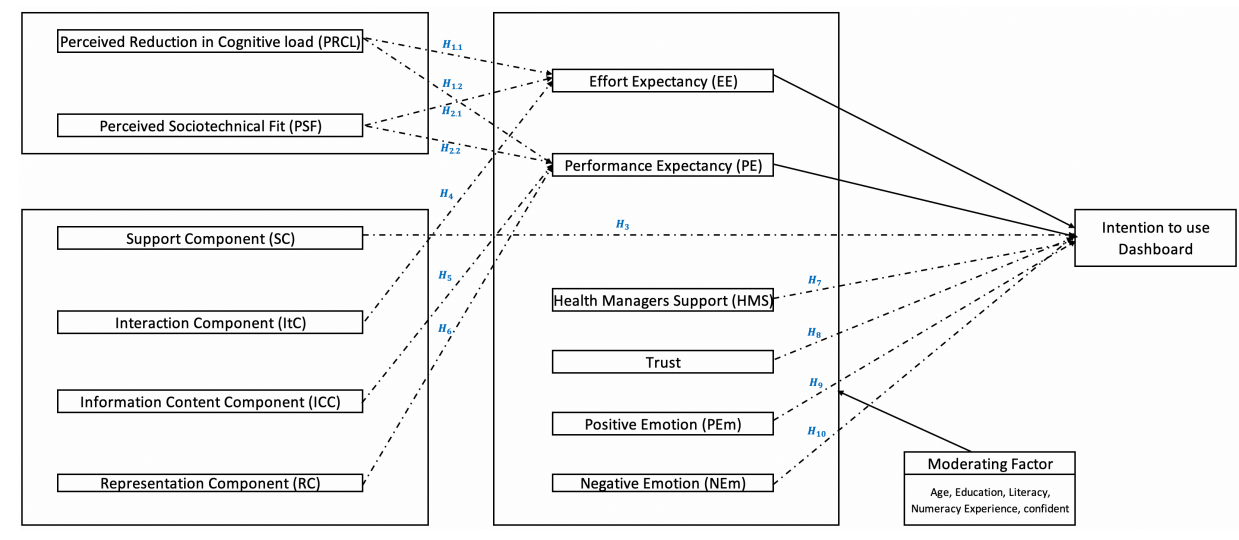

Figure 3. Proposed theoretical model of dashboard acceptance and use in healthcare

\section{Discussion}

The main aim of employing information technology in healthcare is to improve clinical care, processes and workflows. Various types of applications have been developed and introduced, along with advances in computer science and technology in healthcare. Accordingly, many studies have been undertaken in the healthcare context to evaluate the technology applications in this field which are called evaluation studies. Evaluating technology adoption and use in healthcare or any other industry help to identify to what extent the application of the technology has been successful and can guide the managers toward better managing its use. In particular, technology adoption studies help decisionmakers to examine the level of technology acceptance and to identify factors which have vital roles in the successful adoption and use of technology. Various models (section 2) have been utilised to examine technology adoption, acceptance and use in healthcare.

Thus, in this study, the overall aim was to identify factors affecting the dashboard adoption and acceptance in healthcare with regards to the constructs recommended by the existing technology adoption models. We believe the identified factors from this study can be considered to improve the adoption and acceptance of dashboard by users in the healthcare context.
We found out not only the technology and its characteristics but the external environment, e.g., government regulation in healthcare, the movement toward more transparent reporting, policies and regulations related to the integration of patientgenerated health data into the health information technologies; characteristics of the healthcare organisation, e.g., hospitals' norms, value, and regulations, volume, and resource commitment; and users' characteristics, e.g., demographic characteristics, graph literacy, health literacy, numeracy, and visual literacy have vital roles in the decision to adopt and use dashboards in healthcare organisations.

These findings enabled us to propose a new model which can be used to evaluate dashboard adoption, acceptance and use in healthcare. In our model, we have suggested new exogenous and endogenous variables which have not been tested in previous studies.

Based on our model, two new factors, perceived reduction in cognitive load and sociotechnical fit have been identified as two exogenous variables which affect effort expectancy and performance expectancy. Indeed, if users perceive that new technology fits with their organisational norms, tasks, needs and cognitions, it would have a positive effect on their beliefs in using the system. So, to better understand user acceptance of dashboard in the healthcare domain, evaluation studies need to take into account how well the implemented system fits with users' cognition, needs, task and organisational norms. 
Moreover, we have also identified trust, healthcare professional managers support and the emotional reaction as new endogenous variables that affect the users' intention to use a new system. Besides, the characteristics of dashboards, including the quality of the information content, the representation of the information, users interaction (as new exogenous variables) and the supports which is provided by the system (as a new endogenous variable) were other factors which identified to be effective in dashboard adoption and use by users.

Although this study enabled us to discover several new factors, we were unable to identify important factors such as social influence in using dashboards in healthcare. We believe such results can be because of two reasons. First, in most reviewed articles, healthcare professionals were the primary users of dashboards, which unlike patients who are heavily influenced by their physicians, family, and friends in the use of technology in their care process, may not be significantly influenced by their colleagues in the use of dashboards in their practice. Second, it can be related to the number of articles which were used in the analysis section of this study. We argue, if more studies are considered, other effective factors in dashboard acceptance and use can be found.

In our opinion, the findings of this study are essential for understanding dashboard adoption and use in healthcare. Therefore, we believe the factors and hypotheses presented in our model needs to be incorporated into evaluation models or frameworks that focus on dashboards adoption and use in healthcare.

\section{Conclusion}

The review identified 53 effective factors in dashboard adoption and use in healthcare, which were grouped into ten categories. Besides, an evaluation model was proposed considering the identified factors and construct recommended by previous technology adoption model and framework.

In the first phase of the study, we conducted a systematic literature review to identified factors associated with dashboard adoption and acceptance. These factors were then classified according to the constructs proposed by previous models. For those factors which could not be classified based on previous models, we have added them as new factors to the model. The new factors identified from this study are as follow; perceived reduction in cognitive load, perceived sociotechnical fit, healthcare professionals support, trust, emotional reaction and dashboard's components characteristics. The results show that the perceived sociotechnical fit and reduction in cognitive load effect users' beliefs (performance-effort expectancy), which in turn affect the user intention to use dashboards. Furthermore, healthcare professionals support, trust, and emotional reaction were other identified factors affecting the intention to use dashboards as decision aid tools in healthcare. This work exemplifies a new generation of technology adoption and use model which explicitly accommodates the peculiarity of the technology itself and the application context (in this case healthcare).

However, despite the results of this study and its valuable contribution, it also should be mentioned that this review has a few limitations that might affect its generalisability. The first limitation is that the data analyses in this study come from the published literature only. However, the proposed model can be tested by future studies. Secondly, our study does not include every paper published on the topic, but it provides a reasonable synthesis of factors which might lead to adoption and acceptance of dashboards in healthcare.

\section{Acknowledgments}

This study is supported by the Irish Research Council and Galway Clinic Hospital.

\section{References}

[1] M. I. Mashinchi, A. Ojo, and F. J. Sullivan, "Analysis of Business Intelligence Applications in Healthcare Organizations," in Proceedings of the 52nd Hawaii International Conference on System Sciences, 2019, pp. 41554164, doi: http://hdl.handle.net/10125/59853.

[2] A. Franklin et al., "Dashboard visualizations: Supporting real-time throughput decision-making," J. Biomed. Inform., vol. 71, pp. 211-221, 2017, doi: $10.1016 /$ j.jbi.2017.05.024.

[3] J. G. Dolan, P. J. Veazie, and A. J. Russ, "Development and initial evaluation of a treatment decision dashboard," BMC Med. Inform. Decis. Mak., vol. 13, no. 1, pp. 2-9, 2013, doi: 10.1186/1472-6947-12-24.

[4] A. Khan, H. Mukhtar, H. F. Ahmad, M. A. Gondal, and Q. M. Ilyas, "Improving Usability through Enhanced Visualization in Healthcare," Proc. 2017 IEEE 13th Int. Symp. Auton. Decentralized Syst. ISADS 2017, pp. 3944, 2017, doi: 10.1109/ISADS.2017.36.

[5] R. J. Koopman et al., "Physician information needs and electronic health records (EHRs): Time to reengineer the clinic note," J. Am. Board Fam. Med., vol. 28, no. 3, pp. 316-323, 2015, doi: 10.3122/jabfm.2015.03.140244.

[6] M. Isazad Mashinchi, A. Ojo, and F. J. Sullivan, "Investigating Analytics Dashboards' Support for the Value-based Healthcare Delivery Model," Proc. 53rd Hawaii Int. Conf. Syst. Sci., pp. 3659-3668, 2020, doi: $10.24251 /$ hicss. 2020.448

[7] M. Chiasson, M. Reddy, B. Kaplan, and E. Davidson, "Expanding multidisciplinary approaches to healthcare information technologies: What does information systems offer medical informatics?," Int. J. Med. Inform., vol. 76, pp. S89-S97, 2007, doi: 10.1016/j.ijmedinf.2006.05.010.

[8] J. C. Wyatt and J. L. Y. Liu, "Basic concepts in medical informatics," $J$. Epidemiol. Community Health, vol. 56, no. 11, pp. 808-812, 2002, doi: 10.1136/jech.56.11.808

[9] R. Haux, "Aims and tasks of medical informatics," Int. J. Med. Inform., vol. 44, no. 1, pp. 9-20, 1997, doi: 10.1016/S1386-5056(97)01254-9.

[10]H. Heathfield, D. Pitty, and R. Hanka, "Evaluating information technology in health care: Barriers and challenges," Br. Med. J., vol. 316, no. 7149, pp 1959-1961, 1998, doi: 10.1136/bmj.316.7149.1959.

[11]V. Venkatesh, J. Y. L. Thong, and X. Xu, "Unified Theory of Acceptance and Use of Technology: A Synthesis and the Road Ahead," J. Assoc. Inf. Syst., vol. 17 , no. 5, pp. 328-376, 2016

[12]M. M. Kamal, "IT innovation adoption in the government sector: Identifying the critical success factors," J. Enterp. Inf. Manag., vol. 19, no. 2, pp. 192 222, 2006, doi: 10.1108/17410390610645085.

[13]R. M. Abbas, N. Carroll, and I. Richardson, "In technology we trust: Extending TAM from a healthcare technology perspective," in Proceedings 2018 IEEE International Conference on Healthcare Informatics, ICHI 2018 , 
2018, pp. 348-349, doi: 10.1109/ICHI.2018.00051

[14]J. P. Wisdom, K. H. B. Chor, K. E. Hoagwood, and S. M. Horwitz, "Innovation adoption: A review of theories and constructs," Adm. Policy Ment Heal. Ment. Heal. Serv. Res., vol. 41, no. 4, pp. 480-502, 2014, doi: 10.1007/s10488-013-0486-4.

[15]S. A. Adeshina and A. Ojo, "Factors for e-voting adoption - analysis of general elections in Nigeria," Government Information Quarterly, Elsevier Ltd, pp. 1-12, 2017

[16]Venkatesh, Morris, Davis, and Davis, "User Acceptance of Information Technology: Toward a Unified View,” $M I S Q$., vol. 27, no. 3, p. 425, 2003, doi: $10.2307 / 30036540$.

[17]P. Thomas, "Information systems success and technology acceptance within a government organization," 2008

[18]Venkatesh, Thong, and Xu, "Consumer Acceptance and Use of Information Technology: Extending the Unified Theory of Acceptance and Use of Technology," MIS Q., vol. 36, no. 1, pp. 157-178, Oct. 2012, doi: $10.2307 / 41410412$

[19]J. Mütterlein and T. Hess, "Immersion, Presence, Interactivity: Towards a Joint Understanding of Factors Influencing Virtual Reality Acceptance and Use," 2017.

[20]A. Fuad and C.-Y. Hsu, "UTAUT for HSS: initial framework to study health IT adoption in the developing countries," F1000Research, vol. 7, p. 101, Jan. 2018, doi: 10.12688/f1000research.13798.1.

[21]K. Lee et al., "A novel concept for integrating and delivering health information using a comprehensive digital dashboard: An analysis of healthcare professionals' intention to adopt a new system and the trend of its real usage," Int. J. Med. Inform., vol. 97, pp. 98-108, 2017, doi: 10.1016/j.ijmedinf.2016.10.001

[22]C. E. Ward, L. Morella, J. M. Ashburner, and S. J. Atlas, "An interactive, allpayer, multidomain primary care performance dashboard," J. Ambul. Care Manage, vol. 37, no. 4, pp. 339-348, 2014, doi: 10.1097/JAC.0000000000000044.

[23]J. G. Nayak, A. L. Hartzler, L. C. Macleod, J. P. Izard, B. M. Dalkin, and J. L. Gore, "Relevance of graph literacy in the development of patient-centered communication tools," Patient Educ. Couns., vol. 99, pp. 448-457, 2016, doi: 10.1016/j.pec.2015.09.009

[24]J. Izard, A. Hartzler, D. I. Avery, C. Shih, B. L. Dalkin, and J. L. Gore, "Usercentered design of quality of life reports for clinical care of patients with prostate cancer," Surg. (United States), vol. 155, no. 5, pp. 789-796, 2014 doi: 10.1016/j.surg.2013.12.007.

[25]T. C. Huber, A. Krishnaraj, D. Monaghan, and C. M. Gaskin, "Developing an Interactive Data Visualization Tool to Assess the Impact of Decision Support on Clinical Operations," J. Digit. Imaging, vol. 31, no. 5, pp. 640645, 2018, doi: 10.1007/s10278-018-0065-z.

[26]V. Anand et al., "The development of a congenital heart programme quality dashboard to promote transparent reporting of outcomes," Cardiol. Young, 2015, doi: $10.1017 / \mathrm{S} 1047951115002085$

[27]A. Staib, C. Sullivan, M. Jones, B. Griffin, A. Bell, and I. Scott, "The EDinpatient dashboard: Uniting emergency and inpatient clinicians to improve the efficiency and quality of care for patients requiring emergency admission to hospital," EMA - Emerg. Med. Australas., vol. 29, no. 3, pp. 363-366, 2017, doi: $10.1111 / 1742-6723.12661$.

[28]M. Ann and L. Debra, "Evaluation of a Technology-Enabled Tool to Improve Colorectal Cancer Screening Listen A me r ican A ccen t," vol. 20, no. 1, 2015.

[29]A. L. Hartzler, S. Chaudhuri, B. C. Fey, D. R. Flum, and D. Lavallee, "Integrating Patient-Reported Outcomes into Spine Surgical Care through Visual Dashboards: Lessons Learned from Human-Centered Design," eGEMs (Generating Evid. Methods to Improv. patient outcomes), vol. 3, no. 2, p. 2, 2015, doi: $10.13063 / 2327-9214.1133$.

[30]A. Hakone et al., "PROACT: Iterative Design of a Patient-Centered Visualization for Effective Prostate Cancer Health Risk Communication," IEEE Trans. Vis. Comput. Graph., vol. 23, no. 1, pp. 601-610, 2017, doi: 10.1109/TVCG.2016.2598588.

[31]P. G. Nagy, M. J. Warnock, M. Daly, C. Toland, C. D. Meenan, and R. S. Mezrich, "Informatics in Radiology: Automated Web-based Graphical Dashboard for Radiology Operational Business Intelligence," RadioGraphics, vol. 29, no. 7, pp. 1897-1906, 2009, doi: 10.1148/rg.297095701.

[32]D. Zeng, C. C. Yang, V. S. Tseng, C. Xing, H. C. F. Wang, and D. Hutchison, "LNCS 8040 - Smart Health," 2013, no. August, pp. 66-70.

[33]J. R. Robinson et al., "Improving the value of care for appendectomy through an individual surgeon-specific approach," J. Pediatr. Surg., vol. 53, no. 6, pp. 1181-1186, Jun. 2018, doi: 10.1016/j.jpedsurg.2018.02.081.

[34]M. Field, K. Fong, and C. Shade, "Use of Electronic Visibility Boards to Improve Patient Care Quality, Safety, and Flow on Inpatient Pediatric Acute Care Units," J. Pediatr. Nurs., vol. 41, pp. 69-76, Jul. 2018.

[35]G. Welch et al., "An internet-based diabetes management platform improves team care and outcomes in an urban latino population," Diabetes Care, 2015, doi: $10.2337 / \mathrm{dc} 14-1412$

[36]G. Welch, N. A. Allen, S. E. Zagarins, K. D. Stamp, S. E. Bursell, and R. J. Kedziora, "Comprehensive Diabetes Management Program for Poorly Controlled Hispanic Type 2 Patients at a Community Health Center," Diabetes Educ., vol. 37, no. 5, pp. 680-688, 2011, doi: 10.1177/0145721711416257.

[37]S. J. Fonda, C. A. Paulsen, J. Perkins, R. J. Kedziora, D. Rodbard, and S. E. Bursell, "Usability test of an internet-based informatics tool for diabetes care providers: The comprehensive diabetes management program," Diabetes
Technol. Ther., vol. 10, no. 1, pp. 16-24, 2008, doi: 10.1089/dia.2007.0252.

[38]A. L. Hartzler, J. P. Izard, B. L. Dalkin, S. P. Mikles, and J. L. Gore, "Design and feasibility of integrating personalized PRO dashboards into prostate cancer care," J. Am. Med. Informatics Assoc., vol. 23, no. 1, pp. 38-47, 2015 , doi: 10.1093/jamia/ocv101.

[39]D. Desantis, R. J. Baverstock, A. Civitarese, R. T. Crump, and K. V. Carlson, "A clinical perspective on electronically collecting patient-reported outcomes at the point-of-care for overactive bladder," Can. Urol. Assoc. J., vol. 10, no. 11-12, pp. E359-E366, 2016, doi: 10.5489/cuaj.3757.

[40]R. J. Koopman et al., "A diabetes dashboard and physician efficiency and accuracy in Accessing data needed for high-quality diabetes care," Ann. Fam. Med., vol. 9, no. 5, pp. 398-405, 2011, doi: 10.1370/afm.1286.

[41]B. E. Dixon, A. M. Jabour, E. O. K. Phillips, and D. G. Marrero, "An informatics approach to medication adherence assessment and improvement using clinical, billing, and patient-entered data," J. Am. Med. Informatics Assoc., 2014, doi: 10.1136/amiajnl-2013-001959.

[42]K. Daley, J. Richardson, I. James, A. Chambers, and D. Corbett, "Clinical dashboard: use in older adult mental health wards," Psychiatrist, 2013, doi: 10.1192/pb.bp. 111.035899

[43]R. M. Ratwani and A. Fong, “'Connecting the dots': Leveraging visual analytics to make sense of patient safety event reports," J. Am. Med. Informatics Assoc., vol. 22, no. 2, pp. 312-317, 2014, doi: 10.1136/amiajnl2014-002963.

[44]V. Bahl, S. R. McCreadie, and J. G. Stevenson, "Developing dashboards to measure and manage inpatient pharmacy costs," Am. J. Heal. Pharm., vol. 64 no. 17, pp. 1859-1866, 2007, doi: 10.2146/ajhp060596.

[45]A. Oeser, J. Gaebel, A. Dietz, S. Wiegand, and S. Oeltze-Jafra, "Information architecture for a patient-specific dashboard in head and neck tumor boards," Int. J. Comput. Assist. Radiol. Surg., vol. 13, no. 8, pp. 1283-1290, 2018, doi 10.1007/s11548-018-1741-7.

[46]L. Jeffs, S. Beswick, J. Lo, Y. Lai, A. Chhun, and H. Campbell, "Insights from staff nurses and managers on unit-specific nursing performance dashboards: A qualitative study," BMJ Qual. Saf., vol. 23, no. 12, pp. 1001100, 2014 doi: 10.1136 /bmjqs-2013-002595.

[47]A. F. Simpao et al., "Optimization of drug-drug interaction alert rules in a pediatric hospital's electronic health record system using a visual analytic dashboard," J. Am. Med. Informatics Assoc., vol. 22, no. 2, pp. 361-369, 2014 doi: 10.1136/amiajnl-2013-002538.

[48]J. McMenamin, R. Nicholson, and K. Leech, "Patient Dashboard: the use of a colour-coded computerised clinical reminder in Whanganui regional general practices," J. Prim. Health Care, vol. 3, no. 4, pp. 307-310, 2011

[49]J. Bernard, D. Sessler, J. J. Kohlhammer, and R. A. Ruddle, "Using Dashboard Networks to Visualize Multiple Patient Histories: A Design Study on Post-operative Prostate Cancer," IEEE Trans. Vis. Comput. Graph., vol. 25 , no. 3, pp. 1615-1628, 2018, doi: 10.1109/TVCG.2018.2803829.

[50]N. Martin, J. Bergs, D. Eerdekens, B. Depaire, and S. Verelst, "Developing an emergency department crowding dashboard: A design science approach," Int. Emerg Nurs, vol 39 pp. 68-76, Jul. 2018, doi: https://doi.org/10.1016/j.ienj.2017.08.001.

[51]T. R. Talbot et al., "Sustained reduction of ventilator-associated pneumonia rates using Real-Time course correction with a ventilator bundle compliance dashboard," Infect. Control Hosp. Epidemiol., 2015, doi: 10.1017/ice.2015.180

[52]L. G. Militello et al., "Evaluating a modular decision support application for colorectal cancer screening," Appl. Clin. Inform., vol. 8, no. 1, pp. 162-179, 2017, doi: 10.4338/ACI-2016-09-RA-0152.

[53]N. S. D. G. D. F. H. H. B. I. M. R. C. Crouch;" "Software Prototyping- A case report of refining user requirements for a health information exchange dashboard," Appl. Clin. Inform., vol. 7, no. 01, pp. 22-32, 2016, doi: http://dx.doi.org/10.4338/ACI-2015-07-CR-0091.

[54]H. C. Lin, H. C. Wu, C. H. Chang, T. C. Li, W. M. Liang, and J. Y. W. Wang, "Development of a real-time clinical decision support system upon the web mvc-based architecture for prostate cancer treatment, BMC Med. Inform. Decis. Mak., vol. 11, no. 1, 2011, doi: 10.1186/1472-6947-11-16.

[55]K. Bollaerts, T. De Smedt, K. Donegan, L. Titievsky, and V. Bauchau, "Benefit-Risk Monitoring of Vaccines Using an Interactive Dashboard: A Methodological Proposal from the ADVANCE Project," Drug Saf., vol. 41, no. 8, pp. 775-786, 2018, doi: 10.1007/s40264-018-0658-y.

[56]R. De Croon, J. Klerkx, and E. Duval, "Design and evaluation of an interactive proof-of-concept dashboard for general practitioners," in Proceedings - 2015 IEEE International Conference on Healthcare Informatics, ICHI 2015, 2015, pp. 150-159, doi: 10.1109/ICHI.2015.25.

[57]J. Starmer and D. Giuse, "A real-time ventilator management dashboard: toward hardwiring compliance with evidence-based guidelines," in $A M I A \ldots$ Annual Symposium proceedings / AMIA Symposium. AMIA Symposium, 2008, vol. 2008, pp. 702-706. 